\title{
Durability and chemical resistance of nanoparticles fly ash and silica fume belite cement pastes against sulfate and chloride aggressive media- Part II
}

\author{
H.H.M. Darweesh a, *
}

a Refractories, Ceramics and Building Materials Department, National Research Centre, Cairo, Egypt.

*Corresponding author Email: hassandarweesh2000@yahoo.com

DOI: https://doi.org/10.34256/nnxt2141

Received: 05-08-2021; Revised: 10-12-2021; Accepted: 12-12-2021; Published: 16-12-2021

Abstract: The durability (chemical resistence) of the Portland cement (OPC), belite cement (BC) and the optimum belite cement (B4), which their physical and chemo/mechanical properties were perviously investigated in Part I, against $4 \% \mathrm{MgSO}_{4}$ and $4 \% \mathrm{MgCl}_{2}$ solutions up to 12 months in terms of compressive strength, total sulfate and total chloride was evaluated and studied. Results showed that the optimum belite cement (B4) containing $15 \%$ High pulverized fly ash (HPFA) and $5 \%$ Silica fume (SF) could be resisted up to 6 months, while that of BC could be withstood only up to 5 months, and the OPC could not resist more than three months of immersion in $4 \%$ $\mathrm{MgSO}_{4}$ solution. The compressive strength values exhibited by the samples immesed in sulfate solution at 3, 5 and 6 months of immersion were $83.81,76.38$ and $91.13 \mathrm{MPa}$, respectively. The same trend was displayed when the same samples were exposed to $4 \% \mathrm{MgCl}_{2}$ solution. The compressive strength values exhibited by the same samples exposed to chloride solution at 3, 5 and 6 months of immersion were 84.49, 82.23 and $93.32 \mathrm{MPa}$, respectively. The total sulfate and chloride contents were enhanced with immesion time up to 12 months, but their values were the minimum with B4 and the maximum with OPC, while with BC were the medium. The optimum cement batch (B4) achieved the highest resistance where it recorded the lowest values for sulfate and chloride ions, but the OPC exhibited the lowest resistance where it recorded the highest values of sulfate and chloride contents at all immersion ages till 12 months.

Keywords: Nanomaterials, Belite cement, Fly ash, Silica fume, Durability, Strength, Total sulfate, Total chloride.

\section{Introduction}

\subsection{Scope of the problem}

The gradual and continual dominance of cementitious building materials for various constructions is a response due to its increased strength, resistance and versatility when compared with other building materials, e.g. steel, glass, wood and so on. The used raw materials to produce cementing building composites are too cheap and largely available. The exposure of building structures produced by cementing materials to different aggressive media needs to improve the durability performance of these structures. One of the effective methods to improve the performance of cementing composites which is recently gaining an attention is the use of nanotechnology. Generally, materials with sizes ranged between 0.1 to $100 \mathrm{~nm}$ are known as nanomaterials. Increasing the durability of cementing composites by the use of nanomaterials could be associated with its smaller size which refines the micro- and nanostructures of the composites. The used nanomaterials in cementing building composites often possess active pozzolanic characteristics to create some hydrates, and the relatively densification of the micro- and nanostructure were improved [1-5]. Chemical reactions of the nanopozzolanic materials with the evolved calcium hydroxide, or free lime $\mathrm{Ca}$ $(\mathrm{OH})_{2}$ due to hydration in the pore solution of cementing composites often form more calcium silicate hydrate which soon precipitated in the pore structure of the hardened cement pastes. This in turn decreases the total porosity and increases the bulk density. Moreover, this was positively reflected on the mechanical strength of cement structures. The hydration reactions of Portland cement with water have also been found to be expedited in the presence of nanomaterials. This resulted in the formation of more calcium hydroxide [4-9]. This pointed to increase the rate of hydration process. This can be contributed to the nanomaterials that are serving as nucleation site areas for the formation of hydration products due to its 
high fineness [10-14]. Many recent studies [15-24] have proved that the existence of nanomaterials inside the cementing composites revealed an enhancement in the formation of calcium hydroxide at early hydration ages [4-6]. Silicate chain is often formed due to the existence of nanomaterials in cementing composites, This has also been found to increase the resistance of the composites against to the various aggressive chemical attacks [7-11]. Not only is the durability improvement of cementing composites due to the use of nanomaterials, but also the expensive cement content is reduced, where the use of about $1 \mathrm{~kg}$ of nanomaterials will result in a reduction of about $4 \mathrm{~kg}$ of cement to exhibit improved characteristics [6-8].

Very important improvements in the permeability characteristics of cement and/or concrete mixtures containing nano- $\mathrm{SiO}_{2}$ and nano clay at a very low dosage was reported [14]. The enhancement of durability characteristics of cementing composites with the presence of nanomaterials is generally contributed to the pore filling, good compaction and nuclei activating ability of the nanomaterials [18-23]. Though the benefits due to the use of nanomaterials in cementing composites, it is important to ensure that these nanomaterials are well dispersed in the matrix of cement composites. This has been found to result in consequential creation of weak areas and voids in this cementing matrix $[15,24]$.

\subsection{Objectives of the study}

To propel more applications of nano materials improve and enhance the durability performance of cementitious composites, the study was conducted to evaluate the influence of nanomaterials on the durability properties of cementing composites. The durability performance of cementing composites was studied in terms of permeability and resistance to some aggressive chemical media attacks as $\mathrm{MgSO}_{4}$ and $\mathrm{MgCl}_{2}$ solutions up to 12 months.

\section{Experimental}

\subsection{Raw materials}

The used raw materials in the current research study (Part II) are Ordinary Portland cement (OPC Type I- CEM I 42,5R), High belite cement (HBC), high pulverized flay ash (HPFA) and silica fume (SF). The OPC and HBC samples were provided by the new cement factory, Sohag, Egypt, while HPFA sample was provided from a local plant, Giza, Egypt. The SF sample was supplied by the ferrosilicon alloys company, Edfo, Egypt. The blaine surface areas of the four raw materials were $3400,3763,4150$ and $19230 \mathrm{~cm}^{2} / \mathrm{g}$, respectively. The blaine surface areas of OPC and HBC cements were carried out by the "Air Permeability Apparatus", while those of PFA and SF were received as it is from the factories.

The chemical analysis of the OPC, HBC, HPFA and SF specimens as measured by X-ray florescence technique (XRF) is shown in Table 1. The mineralogical phase composition of the used OPC and $\mathrm{HBC}$ as provided by the factory is given in Table 2, while the batch composition is recorded in Table 3 .

Table 1 Chemical analysis of the raw materials, wt.\%.

\begin{tabular}{|l|l|l|l|l|l|l|l|l|l|l|l|}
\hline $\begin{array}{c}\text { Oxide } \\
\text { Materials }\end{array}$ & $\mathbf{S i O}_{2}$ & $\mathbf{A l}_{2} \mathbf{O}_{3}$ & $\mathrm{Fe}_{2} \mathbf{O}_{3}$ & $\mathbf{C a O}$ & $\mathbf{M g O}$ & $\mathbf{N a}_{2} \mathbf{O}$ & $\mathbf{K}_{2} \mathbf{O}$ & $\mathbf{S O}_{3}$ & $\begin{array}{c}\text { Insoluble } \\
\text { residue }\end{array}$ & $\begin{array}{c}\text { LOI } \\
\text { Total, } \\
\%\end{array}$ \\
\hline OPC & 20.41 & 5.51 & 3.64 & 61.53 & 1.60 & 1.01 & 1.16 & 2.07 & 1.63 & 1.44 & 100 \\
\hline $\mathrm{HBC}$ & 23.62 & 3.45 & 4.28 & 57.54 & 4.89 & 0.07 & 0.13 & 2.43 & 0.77 & 1.82 & 100 \\
\hline $\mathrm{FA}$ & 50.53 & 31.64 & 6.05 & 5.13 & 1.47 & 0.76 & 3.14 & 0.17 & 0.42 & 1.51 & 100 \\
\hline $\mathrm{SF}$ & 93.15 & 0.11 & 0.15 & 1.12 & 0.32 & 0.08 & 0.41 & 0.41 & --- & 0.71 & 100 \\
\hline
\end{tabular}

Table 2 Mineralogical constituents of OPC and HBS cement samples, wt. \%.

\begin{tabular}{|l|l|l|l|l|}
\hline \multicolumn{1}{|c|}{ Phase Cement } & \multicolumn{1}{c|}{$\boldsymbol{C}_{\mathbf{3}} \mathbf{S}$} & \multicolumn{1}{c|}{$\boldsymbol{\beta}-\mathbf{C}_{\mathbf{2}} \mathbf{S}$} & \multicolumn{1}{c|}{$\mathbf{C}_{\mathbf{3}} \mathbf{A}$} & \multicolumn{1}{c|}{$\mathbf{C}_{\mathbf{4}} \mathbf{A F}$} \\
\hline OPC & 48.37 & 24.72 & 8.28 & 11.45 \\
\hline HBC & 29.12 & 42.87 & 2.03 & 12.57 \\
\hline
\end{tabular}


Table 3 Mix composition from the used raw materials, wt. \%.

\begin{tabular}{|c|c|c|c|c|}
\hline Materials Mixes & OPC & HBC & HPFA & SF \\
\hline P0 & 100 & ---- & ---- & ---- \\
\hline B0 & 100 & ---- & ---- & ---- \\
\hline B1 & ---- & 95 & 5 & ---- \\
\hline B2 & ---- & 90 & 5 & 5 \\
\hline B3 & ---- & 85 & 10 & 5 \\
\hline B4 & ---- & 80 & 15 & 5 \\
\hline B5 & ---- & 75 & 20 & 5 \\
\hline
\end{tabular}

\subsection{Preparation and methods}

There are five blended cement batches composed from Belite cement (BC), high pulverized fly ash (HPFA) and silica fume (SF). The belite cement batches were composed of BC, HPFA and SF as 100:0:0, 95:5:0, 90:5:5, 85:10:5, 80:15:5, and 75:20:5 having the symbols: B0, B1, B2, B3, B4 and B5, respectively (Table 3 ). The blending process of the various cement batches was done in a porcelain ball mill using three balls for two hours to assure the complete homogeneity of all cement batches. The physical and mechanical properties of OPC and HBC blended with different ratios of HPFA and a constant ratio of SF $(5 \%)$ were previously investigated in Part I [25]. The optimum cement batch (B4) containing $80 \%$ HBC, $15 \%$ HPFA and 5\% SF was selected to be subjected to sulfate and chloride attacks for 12 months.

In the present study (Part II), the resistance of the selected optimum batch (B4) pastes from Part I against the attack by $4 \% \mathrm{MgSO}_{4}$ and $4 \% \mathrm{MgCl}_{4}$ was evaluated comparing with those of the blank cements (OPC and $\mathrm{HBC}$ ). There are three cement mixes as OPC, $\mathrm{HBC}$ and $\mathrm{B} 4$ having the symbols of $\mathrm{PO}, \mathrm{BO}$ and $\mathrm{B} 4$, respectively. The blending process was mechanically made in a porcelain ball mill containing three balls for one hour to assure the complete homogeneity of all batches. Before casting of cement cubes, all moulds were oiled with a thin film of motor engine oil, to facilitate the release of the cubes from the moulds during the de-moulding. During casting of cement pastes, a certain percentage of Na-lignosulphonate admixture was added to all cement mixtures during mixing to avoid the agglomeration of the nanoparticles of cement powder. Sodium lignosulfonate admixture was applied due to its higher activity than other conventional ones (Figure 1). Each already prepared oil moulds were filled with the premixed cement composite and rammed 10 minutes to remove all air bubbles tapped within the mixture. The moulds were filled to the top surface and smoothed with a suitable flat stainless-steel trowel or spatula to obtain a flat and smooth surface $[26,27]$.

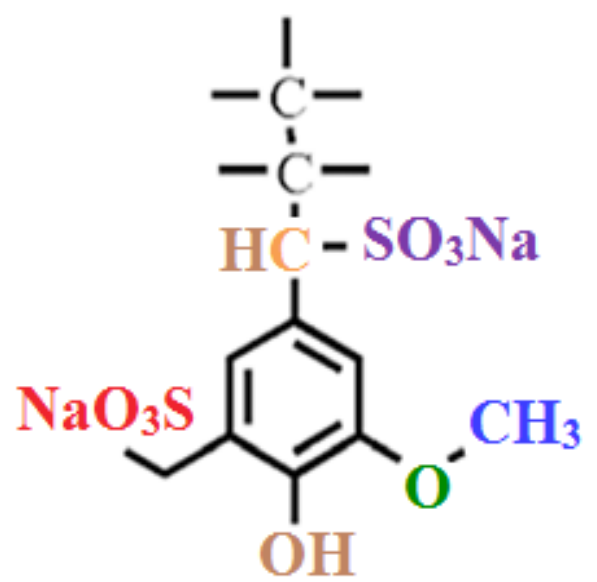

Figure 1 Chemical structure of sodium lignosulphonate.

The cement pastes were mixed using the predetermined water of consistency that was previously determined in Part I [25], then molded into one-inch cubic stainless steel moulds $(2.5 \times 2.5 \times 2.5$ $\mathrm{cm}^{3}$ ), vibrated manually for five minutes, and then on a mechanical vibrator for another five minutes. After casting of all cement cubes, they were covered with a black wet sheet for the first 24 hours to prevent moisture loss. The moulds were kept inside a humidity cabinet for 24 hours at $23 \pm 1{ }^{\circ} \mathrm{C}$ and $100 \%$ R.H., demolded in the following day, and soon cured in water up to 28 days. The 28 days hydrated samples were subjected to compressive strength [28], where the loading was applied perpendicular to the direction of 
the upper surface of the cubes. The compressive strength was calculated from the following equation:

\section{$\mathrm{CS}=\mathrm{L} \quad(\mathrm{KN}) / \mathrm{Sa} \quad\left(\mathrm{cm}^{2}\right) \quad \mathrm{KN} / \mathrm{m}^{2} \quad$ x 102 $\left(\mathrm{Kg} / \mathrm{cm}^{2}\right) / 10.2(\mathrm{MPa})$

Where, $\mathrm{L}$ and Sa are the load taken and the surface area, respectively. After carrying out the compressive strength at each curing time, about $10 \mathrm{~g}$ of the broken samples was dried at $105{ }^{\circ} \mathrm{C}$ for one hour, and then were placed in a solution mixture of $1: 1$ methanol: acetone to stop the hydration, and then kept in an airtight bottle [29-32]. Also, the total sulfate and chloride were measured at each hydration interval. The measured values at 28-days for compressive strength, total sulfate and chloride contents for each cement mix were considered as zero readings.

The rest of samples were then immersed in a freshly prepared $4 \% \mathrm{MgSO}_{4}$ and $4 \% \mathrm{MgCl}_{2}$ solutions up to 12 months noticing that at first, the chloride and sulfate solutions were renewed every 2-3 days so as to keep its concentrations nearly constant $[33,34]$. The total $\mathrm{SO}_{3}$ content [35-37] was determined by placing one gram of the dried sample $\left(W_{1}\right)$ in a beaker containing $300 \mathrm{ml}$ freshly prepared half saturated lime water. The content was stirred for one hour using a magnetic stirrer, and then filtered through a sintered glass funnel G. 4. The residue was washed several times with lime water, and then with distilled water. Add $5 \mathrm{ml}$ conc. $\mathrm{HCl}$ acid (Sp. gr. 1.18) and drop wise $10 \mathrm{ml} \mathrm{BaCl}_{2}(100 \mathrm{~g} / \mathrm{l})$ to the boiling filtrate. The mixture was boiled gently for 5 minutes, let to cool gradually, and then filter. Wash several times with hot distilled water till free from chloride. Thus, the total sulfate content precipitated. Ignite the residue up to $850{ }^{\circ} \mathrm{C}$ for 30 minutes, cool in a desiccator and weigh $\left(\mathrm{W}_{2}\right)$. The total sulfate content was calculated from the following relation:

\section{Total $\mathrm{SO}_{3}, \%=\mathrm{W}_{2} \times 34.3 / \mathrm{W}_{1} \times 100$}

Where, $W_{1}$ is the weight of the original sample, $W_{2}$ is the ignited weight of the residue and 34.3 is the molecular ratio of $\mathrm{SO}_{3}$ to $\mathrm{BaSO}_{4}(0.343)$ multiplied by 100. The total $\mathrm{Cl}^{-}$ions content in the hardened cement pastes was determined by weighing 2 grams of the powdered sample into a stoppered conical flask $\left(M_{1}\right)$. Dispersed with $35 \mathrm{ml}$ dist. water, and then add $10 \mathrm{ml}$ $\mathrm{HNO}_{3}$ acid (Sp. Gr. 1.42). add $50 \mathrm{ml}$ hot water, heat till boiling and keep warm for $10-15 \mathrm{~min}$. Cool to the room temperature and add standard $0.1 \mathrm{~N} \mathrm{AgNO}_{3}$. Add 2-3 $\mathrm{ml}$ nitrobenzene, stopper the flask and shake vigorously to coagulate the precipitate. Add one $\mathrm{ml}$ of ferric indicator $(100 \mathrm{ml}$ saturated ammonium ferric sulfate solution $+10 \mathrm{ml} \mathrm{HNO}_{3}$ ). Titrate using a standard solution of $0.1 \mathrm{~N}$ ammonium thiocyanate till the first permanent red color and weigh $\left(M_{2}\right)$. The total chloride content was then calculated from the next relation:

$$
\text { Total } \mathrm{Cl}^{-}, \%=\mathrm{M}_{1}-\mathrm{M} 2 / \mathrm{M}_{2} \times 100
$$

Where $M_{1}$ is the original weight of the sample, $M_{2}$ is the final weight of the sample. The obtained results of chloride contents must be corrected by subtracting the values of chloride contents of the starting raw materials.

\section{Results and Discussion}

\subsection{Compressive strength ( $4 \% \mathrm{MgSO}_{4}$ )}

The compressive strength of the OPC (P0), HB (B0) and HPFA/SF/HB (B4) cements cured in $4 \%$ $\mathrm{MgSO}_{4}$ solution till 12 months is represented versus immersing time in Figure 2. The compressive strength of the hardened cement pastes of the OPC (P0) slightly enhanced merely up to three months, and then diminished up to 6 months, but sharply declined till 12 months of immersion, i.e. the 28-compressive strength of the pure OPC pastes (P0) can withstand only up to three months in $4 \% \mathrm{MgSO}_{4}$. It is essentially attributed to the fact that at early ages of immersion the total porosity of the hardened cement pastes was nearly the maximum. Therefore, the rate of diffusion of $\mathrm{SO}_{4}{ }^{-2}$ ions could be partially eliminated and only form a white coat on the lateral edges of the samples which prevents the further diffusion of the $\mathrm{SO}_{4}{ }^{-2}$ ions through the cement surfaces $[38,39]$. So, a slight improve in the compressive strength coming from the hydration process and the small activation of $\mathrm{SO}_{4}{ }^{-2}$ ions $[40,41]$. The decrease of compressive strength after 3 months of immersion is principally due to the aggressive attack of the $\mathrm{SO}_{4}^{-2}$ ions so that the cement pastes could not resist the diffusion of $\mathrm{SO}_{4}{ }^{-2}$ ions inside the cement matrix. This gave a big opportunity to some deleterious reactions to take place. This case was often ended by the formation of ettringite and/or gypsum. These phases always cause expansion accompanied by internal minor cracks and the disintegration of the formed hydrates, which are the centers of binding or cementing properties. These are the main reasons responsible for the strength loss [41-43]. Though the values of compressive strength of $B C$ are lower than those of OPC at all immersing times, the BC could be withstood up to five months, and then decreased. This means that the $\mathrm{BC}$ is more resistant against the attack of $\mathrm{SO}_{4}{ }^{-2}$ ions than OPC $[33,34]$. 
The compressive strength of the hardened cement pastes of B4 containing FA and SF enhanced with the increase of immersing time till 6 months, and then declined. Improving of compressive strength is essentially attributed to the decrease of $\mathrm{C}_{3} \mathrm{~A}$ phase because it is very sensitive to $\mathrm{SO}_{4}{ }^{-2}$ ions and it is easily spoiled by these ions. It was in turn compensated with the two pozzolanic mineral admixtures [35], because the FA and/or SF particles are difficult to disintegrate by the sulfate ions due to its high glassy structure and also due to its high contents of silica, and moreover the activation of the BC by HPFA and SF, in addition to the good dispersion by the used admixture, and the good compaction of these pozzolanic materials during moulding. The filling action as well as the relatively lower amount of free lime due to its consumption by the pozzolanic reactions to form $\mathrm{CSH}$ and the rate of $\mathrm{SO}_{4}{ }^{-2}$ ions diffusion into the hardened cement matrix was the minimum because it decreases the permeability [44]. The FA can create soft parts of fresh pastes which improve its plasticity, infill gaps between constituents, compress the contact zone between the various grains and the matured cement [45]. Also, the hydraulic characteristics of both components are well contributed to the less permeability to liquids or gases and mechanical strength improvement. Accordingly, the compressive strength improved and enhanced
$[38,41]$. Lack of compressive strength was related to the evolution of water from the cement matrix into the solution due to the deleterious reactions. It is often followed by an increase in the porosity and permeability. It seemed to speed up the action effect of $\mathrm{SO}_{4}{ }^{2-}$ ions, and hence a strength loss could be expected $[40,46]$. This higher porosity and permeability often accompanied by a more strength loss [43-46]. This was perfectly agreed with that obtained by many investigators $[35,46]$.

Though the $\mathrm{SO}_{4}{ }^{2-}$ ions aggressively attacked the cement matrix after the $6^{\text {th }}$ month of immersion, no visual cracks or any signs of deterioration on the lateral surfaces or edges could be seen by the naked eyes. At the end of the $12^{\text {th }}$ month of immersion, the $\mathrm{SO}_{4}{ }^{2-}$ ions only deposited or adsorbed on the external surfaces or lateral edges of the hardened cement structures and some horizontal minor cracks and little deformation could be seen on the edges of specimens which is likely due to the decalcification of CSH [35,43-46], while the action effect of these sulfate ions are more effective on the OPC pastes where large cracks and swelling were noted. This means that the degree of damage was in the decreasing order: OPC $<\mathrm{HBC}<$ B4. Consequently, it could be concluded that the OPC is more affected by $4 \% \mathrm{MgSO}_{4}$ ions, while the $\mathrm{B} 4$ is the least.

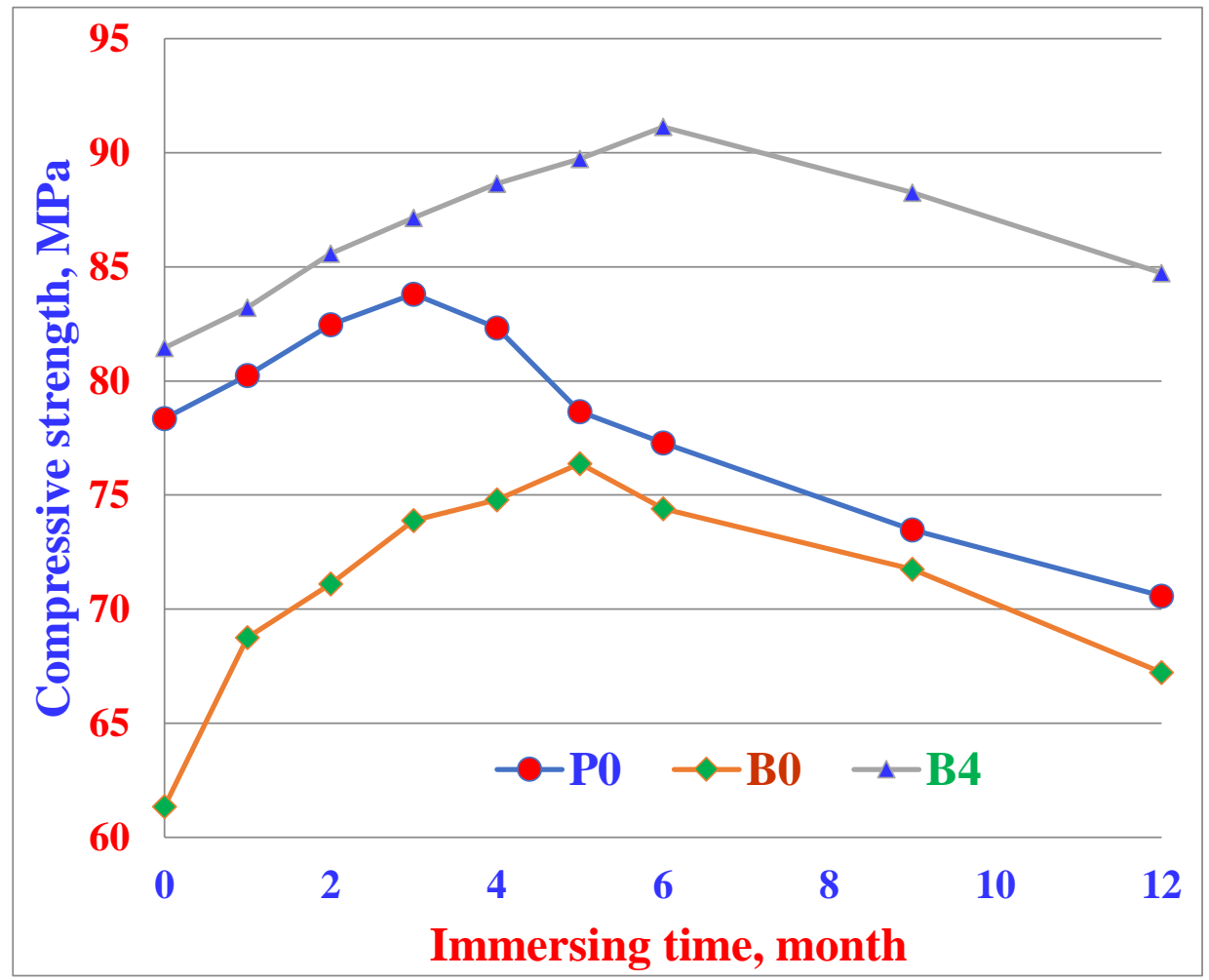

Figure 2 Compressive strength of the OPC, belite and $\mathrm{HPFA} / \mathrm{SF}$ belite cements immersed in $\mathrm{MgSO}_{4}$ solution up to 12 months. 


\subsection{Total sulfate content}

The total $\mathrm{SO}_{4}^{-2}$ content of the OPC (PO), BC (B0) and HPFA/SF/BC (B4) cements cured in $4 \%$ $\mathrm{MgSO}_{4}$ solution up to 12 months is represented versus the immersing time in Figure 3. The total $\mathrm{SO}_{4}{ }^{-2}$ content enhanced with the time of immersing up to 12 months. This is mainly due to the migration of $\mathrm{SO}_{4}{ }^{2-}$ ions into the hardened cement matrix. This in turn reacted with $\mathrm{C}_{3} \mathrm{~A}, \mathrm{C}_{4} \mathrm{AF}$ and $\mathrm{Ca}(\mathrm{OH})_{2}$ to form calcium sulfoaluminate hydrates (ettringite) and/or monosulfate hydrate $[37,42,47]$. The OPC exhibited the highest values of total $\mathrm{SO}_{4}^{-2}$ content, while those of other blended cement pastes (B4) achieved the lowest values nearly at all immersing times, This is principally attributed to the formation of a dense white coat of $\mathrm{SO}_{4}{ }^{2-}$ ions on the lateral surfaces of the immersed specimens. This coat prevents the penetration or diffusion of $\mathrm{SO}_{4}{ }^{2-}$ ions into the matrix of cement pastes. This in turn slows down the aggressive diffusion of the $\mathrm{SO}_{4}{ }^{2-}$ ions $[35,37]$, beside other factors as the good dispersion and good compaction of samples during moulding. Therefore, the pure OPC pastes (PO) are so sensitive to $\mathrm{SO}_{4}{ }^{2-}$ ions that they are highly influenced by these ions $[35,37,42,48]$, noticing that the $\mathrm{BC}(\mathrm{BO})$ recorded the medium values of $\mathrm{SO}_{4}{ }^{2-}$ ions contents at all immersing times.

\subsection{Mechanism of $\mathrm{MgSO}_{4}$ attack}

During the early ages of immersion in $4 \%$ $\mathrm{MgSO}_{4}\left(\mathrm{MS}^{-}\right)$solution, the $\mathrm{MS}^{-}$ions directly reacted with the produced $\mathrm{Ca}(\mathrm{OH})_{2}\left(\mathrm{H}^{-}\right)$from the hydration process to form gypsum $\mathrm{CaCO}_{3} .2 \mathrm{H}_{2} \mathrm{O}\left(\mathrm{CS}^{-} . \mathrm{H}_{2}\right)$ and brucite, $\mathrm{Mg}(\mathrm{OH})_{2}(\mathrm{MH})$ as follows:

$$
\mathrm{MS}^{-}+\mathbf{C H}+\mathbf{2 H} \rightarrow \mathrm{CS}^{-} \cdot \mathrm{H}_{2}+\mathrm{MH}
$$

The insoluble $\mathrm{MH}$ decreases the $\mathrm{pH}$-value of the hydrates. So, the lower pH-value de-stabilizes either $\mathrm{CSH}$ or ettringite. Moreover, no additional ettringite could be formed because the $\mathrm{MS}^{-}$ions further react with $\mathrm{CSH}$ to form more gypsum, $\mathrm{MH}$ and $\mathrm{SiO}_{2}$-gel $[23,33,34]$ as follows:

$$
\begin{aligned}
& \mathrm{C}_{\mathrm{x}} \mathrm{S}_{\mathrm{y}}+\mathrm{MS}^{-}+(3 \mathrm{x}+0.5 \mathrm{y}-\mathrm{z}) \mathrm{H} \rightarrow \mathrm{CS}^{-} \cdot \mathrm{H}_{2}+\mathrm{MH} \\
& +\mathrm{SiO}_{2} \text {-gel }
\end{aligned}
$$

The formed phase $\left(\mathrm{SiO}_{2}\right.$-gel) has no or minor cementing properties than $\mathrm{CSH}$. The $\mathrm{CSH}$ further hydrates to liberate $\mathrm{CH}$ to re-increase the $\mathrm{pH}$-value and establish its equilibrium. But, the liberated lime instead of re-increasing the $\mathrm{pH}$-value, it reacts with $\mathrm{MS}^{-}$ions forming more $\mathrm{CS}^{-} \cdot \mathrm{H}_{2}$ and $\mathrm{MH}$ and so on. Accordingly, the $\mathrm{CS}^{-} \cdot \mathrm{H}_{2}$ and $\mathrm{MH}$ contents increase gradually, whereas the CSH losses its cementing properties leading to further deleterious action. Furthermore, the $\mathrm{MH}$ reacts with the $\mathrm{SiO}_{2}$-gel forming $\mathrm{MSH}$ [43] as follows:

\section{$4 \mathrm{MH}+\mathrm{SiO}_{2}-\mathrm{gel} \rightarrow \mathrm{MSH}$}

The resulting product (MSH) is noncementitious and causes softening of the cement pastes. Hence, the formation of high amounts of gypsum and $\mathrm{MH}$ is the main reason responsible for damaging $[33,34,49,50]$.

\subsection{Compressive strength ( $4 \% \mathrm{MgCl}_{2}$ )}

The compressive strength of the OPC (PO), HB (B0) and HPFA/SF/HB (B4) cements cured in $4 \%$ $\mathrm{MgCl}_{2}$ solution up to 12 months is graphically drawn against immersing time in Figure 4. In case of $\mathrm{MgCl}_{2}$ solution, the compressive strength displayed the same trend with the same samples up to 12 months. The compressive strength of the OPC (P0) enhanced merely up to 3 months of immersion, and then declined. Increasing of the compressive strength is essentially due to the hydration process of the main cement phases, in addition to the initial activation of cement phases by $\mathrm{Cl}^{-}$ions $[35,37]$. Furthermore, the nanograin size particles of the HPFA and SF led to a significant decrease in the diffusion of chloride ions into the hardened cement pastes $[29,33,51]$. Whereas the reduction of compressive strength is mainly contributed to the aggressive attack of the $\mathrm{Cl}^{-}$ions so that the cement pastes could not resist the diffusion of $\mathrm{Cl}^{-}$ions into the cement matrix, i.e. the P0 could not withstand against the attack of $\mathrm{Cl}^{-}$ions except three months. The compressive strength of B0 increased up to 5 months, and then decreased. Though the values of compressive strength of $\mathrm{BC}$ are being lower than those of OPC up to 3 months of immersing, the $B C$ could be withstood only up to four months, and then decreased, i.e. the $\mathrm{BO}$ is more resistant against the attack of $\mathrm{Cl}^{-}$ions than OPC $[33,34]$. Moreover, the compressive strength values after 3 months of immersion were higher than those of PO onward.

The compressive strength of the hardened cement pastes of B4 containing FA and SF enhanced with immersing ages up to 6 months, and then reduced. The increase of compressive strength is mainly due to the pozzolanic reaction of the HPFA and SF [35]. The FA and/or SF particles are also difficult to decompose by the $\mathrm{Cl}^{-}$ions because of its high glassy structure and its high contents of silica. Moreover, the 
activation of the BC by HPFA and SF, in addition to the good dispersion by the used admixture, and the good compaction of these pozzolanic materials due to its filling action as well as the relatively lower amount of free $\mathrm{Ca}(\mathrm{OH})_{2}$ due to its consumption by these pozzolanic materials to form $\mathrm{CSH}$. This made the rate of sulfate ions diffusion into the hardened cement matrix was the minimum because this reduces the permeability to a large extent $[44,45]$. Also, the hydraulic features of both components are well contributed to the less permeability to liquids or even gases and mechanical strength improvement. As a result, the compressive strength tends to increase $[38,41]$. A reduction in the $\mathrm{Cl}^{-}$ions penetration into the hardened cement pastes incorporating nano-sized particles was reported due to the densification capability of the nanomaterials like nanosilica $[33,52]$. Reduction of compressive strength is perhaps contributed to the release of water from the cement pastes into the solution as a result of the detrimental reactions. This usually accompanied with a consequent increase in the porosity and permeability $[53,54]$.

\subsection{Total chloride content}

The total $\mathrm{Cl}^{-}$ions content of the OPC (P0), BC (B0) and HPFA/SFBC (B4) cements cured in $4 \% \mathrm{MgCl}_{2}$ solution up to 12 months is represented versus the immersing time in Figure 5. The total $\mathrm{Cl}^{-}$ions content gradually enhanced with immersing time up to 12 months. It is contributed to the migration of $\mathrm{Cl}^{-}$ions into the hardened cement pastes. This in turn reacted with $\mathrm{C}_{3} \mathrm{~A}$ and $\mathrm{Ca}(\mathrm{OH})_{2}$ to produce calcium chloroaluminate hydrate, $\mathrm{C}_{3} \mathrm{~A} \cdot \mathrm{CaCl}_{2} \cdot \mathrm{H}_{12}[37,42,47]$. The OPC exhibited the highest values of total $\mathrm{Cl}^{-}$ions content, while those of other blended cement pastes (B4) achieved the lowest values, nearly at all immersing times. This is essentially attributed to that at early periods of exposure to $\mathrm{Cl}^{-}$ions (up to 3 months) the $\mathrm{Cl}^{-}$ ions accelerated the rate of hydration due to the formation of $\mathrm{CaCl}_{2}$. After 3 months, the amounts of $\mathrm{CaCl}_{2}$ and $\mathrm{Mg}(\mathrm{OH})_{2}$ were largely and continuously increased, which in turn increased the amount of calcium chloro-aluminate hydrate, $\mathrm{C}_{3} \mathrm{~A} . \mathrm{CaCl}_{2} . \mathrm{H}_{12}$. This could be increased the diffusion of $\mathrm{Cl}^{-}$ions by time. The accumulation of these ions was often followed by more dissociation of the formed CSH from the hydration process. The total $\mathrm{Cl}^{-}$ions of $\mathrm{B} 4$ incorporated HPFA and $\mathrm{SF}$ achieved the lowest $\mathrm{Cl}^{-}$ions content. It is principally attributed to the presence of nanosilica particles because it was more resistant to $\mathrm{Cl}^{-}$ions than in its absence, beside other factors as the good dispersion and good compaction of samples during moulding, i.e. the pure OPC pastes (PO) are so sensitive to $\mathrm{Cl}^{-}$ions that they are highly affected with these ions $[35,37,42,48]$.

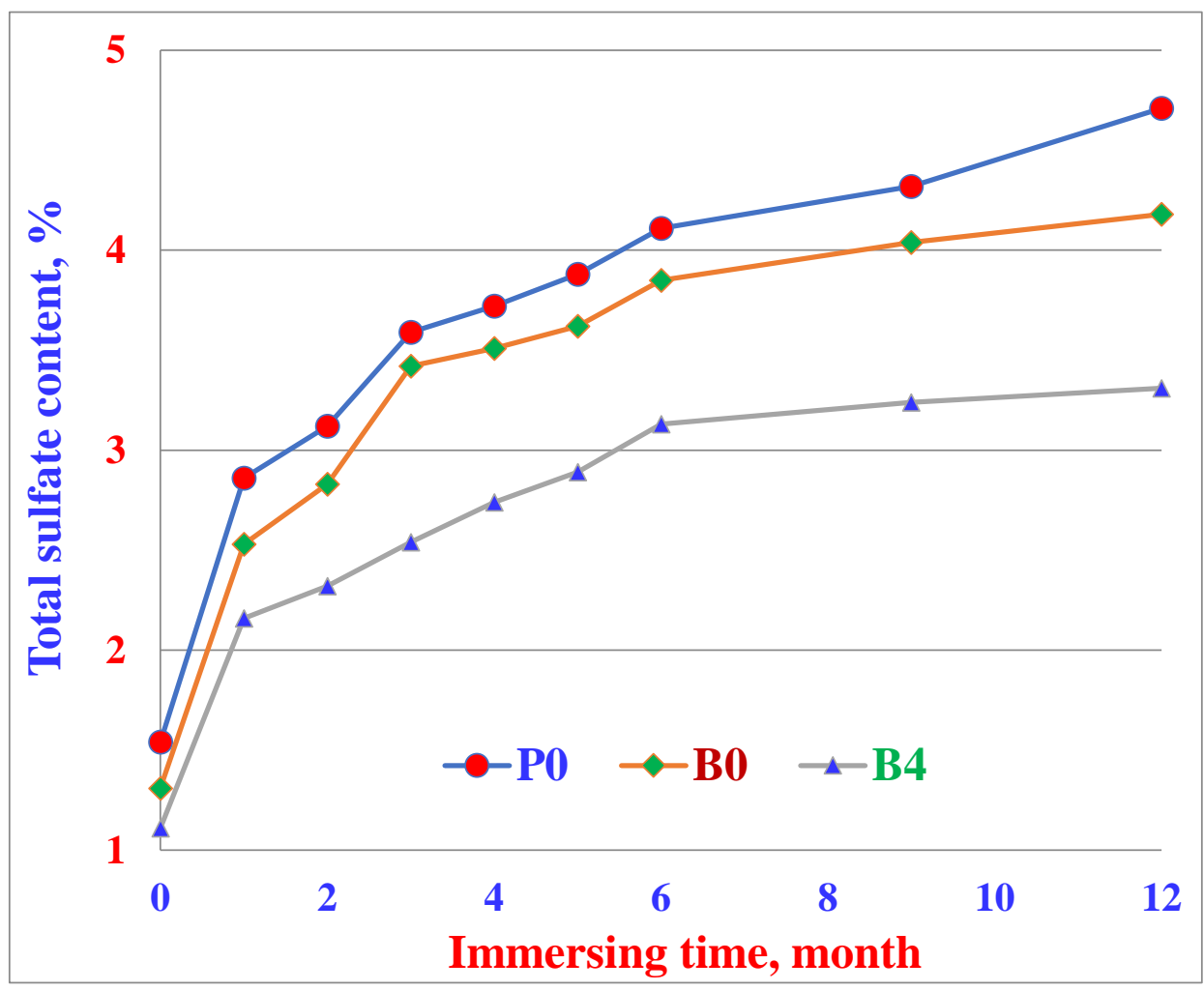

Figure 3 Total sulfate content of the OPC, belite and HPFA/SF belite cements immersed in $\mathrm{MgCl}_{2}$ solution up to 12 months. 


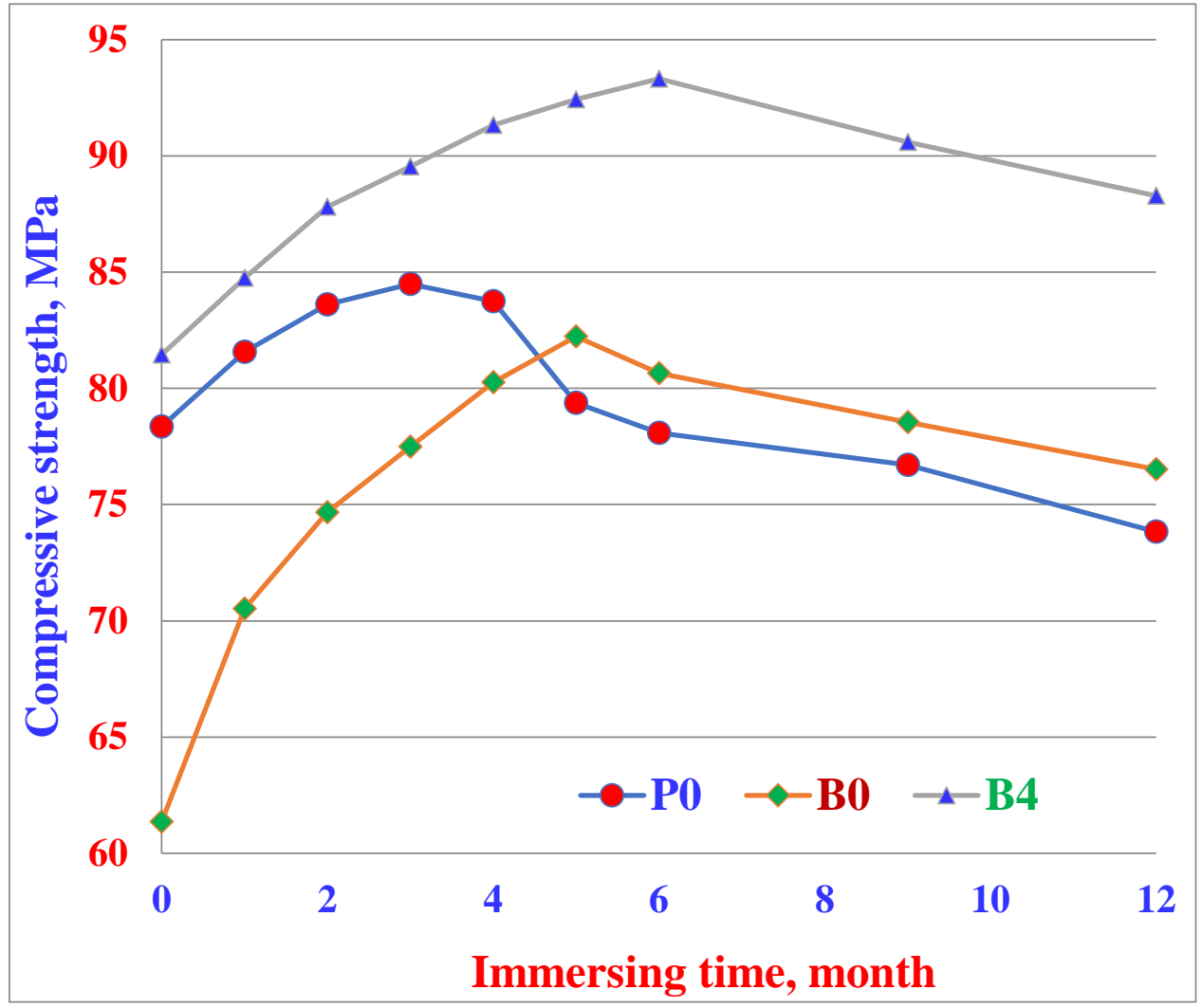

Figure 4 Compressive strength of the OPC, belite and HPFA/SF belite cements immersed in $\mathrm{MgCl}_{2}$ solution up to 12 months.

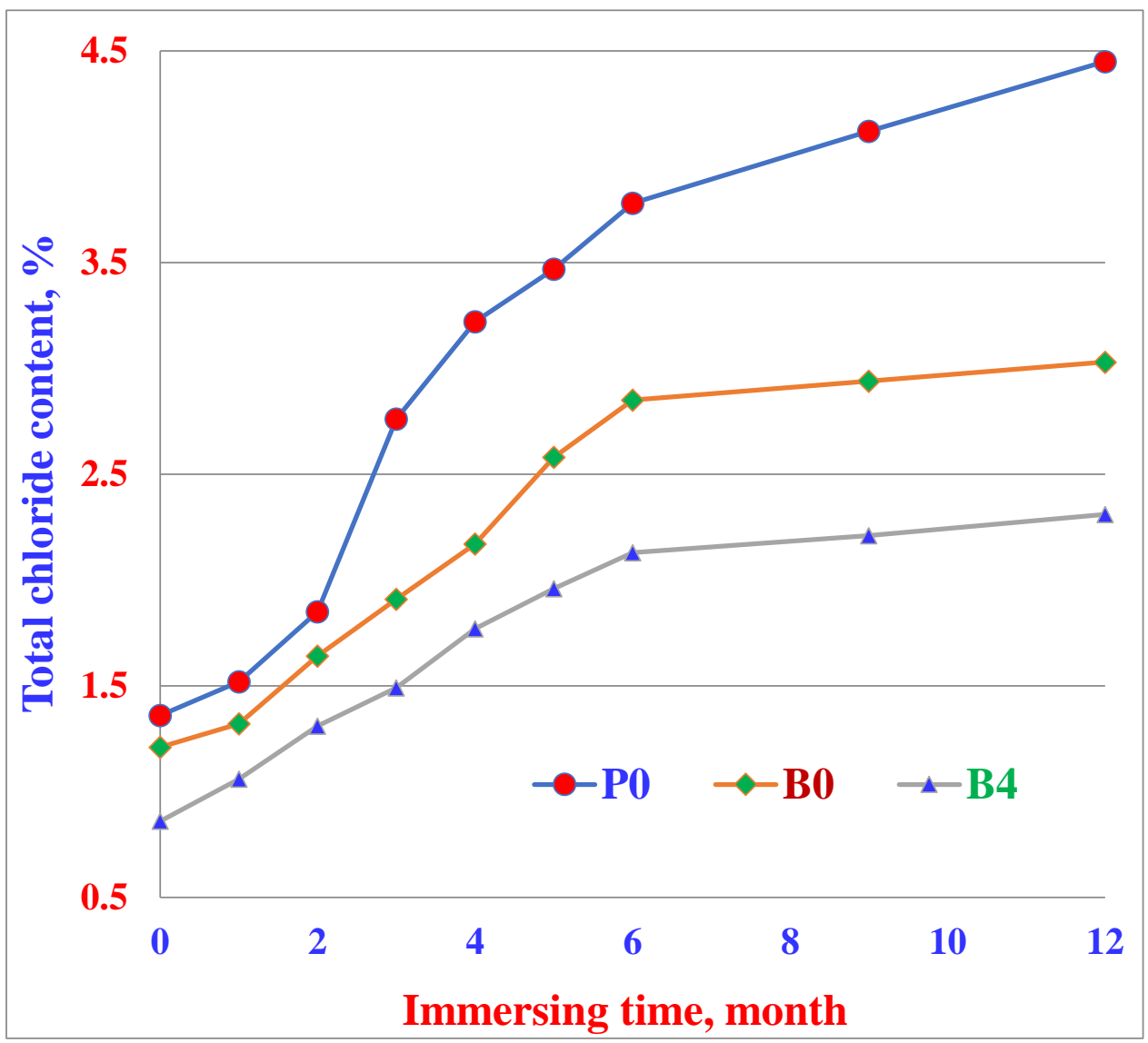

Figure 5 Total chloride content of the OPC, belite and HPFA/SF belite cements immersed in $\mathrm{MgCl}_{2}$ solution up to 12 months. 


\subsection{Mechanism of $\mathrm{MgCl}_{2}$ attack}

During the early ages of immersion in $4 \%$ $\mathrm{MgCl}_{2}\left(\mathrm{MC}^{2-}\right)$ solution, the $\mathrm{MC}^{2--}$ ions directly reacted with the formed $\mathrm{Ca}(\mathrm{OH})_{2}\left(\mathrm{H}^{-}\right)$that is coming from the hydration process to produce calcium chloride $\left(\mathrm{CaCl}_{2}\right)$ and brucite, $\mathrm{Mg}(\mathrm{OH})_{2}(\mathrm{MH})$ as in equation 6 . The resulting $\mathrm{CaCl}_{2}$ could be reacted with alumina-bearing compounds to form chloro-aluminate hydrate $\left(\mathrm{C}_{3} \mathrm{~A} \cdot \mathrm{CaCl}_{2} \cdot \mathrm{H}_{12}\right)$ as in equation $7[23,35,37,55]$.

$$
\begin{aligned}
& \mathrm{MgCl}_{2}+\mathrm{Ca}(\mathrm{OH})_{2} \rightarrow \mathrm{CaCl}_{2}+\mathrm{Mg}(\mathrm{OH})_{2} \\
& \mathrm{CaCl}_{2}+\mathrm{C}_{3} \mathrm{~A} \cdot \mathrm{H}_{12} \rightarrow \mathrm{C}_{3} \mathrm{~A} \cdot \mathrm{CaCl}_{2} \cdot \mathrm{H}_{12}
\end{aligned}
$$

The formed latter hydrate causes a little expansion due to its high crystal growth. It often caused softening of the cement pastes, and its formation is always accompanied by decreasing the compressive strength. This is mainly due to that the $\mathrm{Cl}^{-}$ ions were evidently form a more pore volume on the long-term of immersion, i.e. porous $\mathrm{CSH}$. This allows easier diffusion of $\mathrm{Cl}^{-}$ions by the leaching of $\mathrm{Ca}(\mathrm{OH})_{2}$ and the formation of the very soluble $\mathrm{CaCl}_{2}$. It also reduces the $\mathrm{pH}$ value of the poresolution. Therefore, the net result is a higher degree of deterioration or even the complete damage of the cement structure on the long time, i.e. the excess of the formed $\mathrm{CaCl}_{2}$ is the increase of the deterioration. Furthermore, on the long time the breakdown or even decay of the hardened cement pastes was expected not only due to the formation of $\mathrm{C}_{3} \mathrm{~A} . \mathrm{CaCl}_{2} \cdot \mathrm{H}_{12}$ or leaching of $\mathrm{Ca}(\mathrm{OH})_{2}$, but also associated to the formation of another salts with no cementing or binding properties $[33,43,53,55]$.

\section{General Discussion}

Generally, the resistance of cementing composites is principally contributed to its ability to withstand against the detrimental reactions in the various chemical media to which it is exposed, i.e. the durability performance of cementing composites is mainly depending on the ease and rate of diffusion of the deteriorating ions and fluids into the hardened cement structures. On account of the nature of the used nanomaterials, the nanoparticles could be acted as fillers that could fill the pore volume between the various grains of the cement. Thereby, this could be resulted in a more densified structure with a higher resistance to the diffusion of any deleterious ions. Moreover, the pozzolanic reactions of the nanoparticles with the released free lime or $\mathrm{Ca}(\mathrm{OH})_{2}$ from the hydration of calcium silicate phases of the cement $\left(\mathrm{C}_{3} \mathrm{~S}\right.$ and $\beta-C_{2} S$ ) to form $\mathrm{CSH}-$ gel. Soon, it precipitated in the pore volume of the hardened cement pastes. It will improve the densification parameters of the hardened cement microstructure as water absorption, bulk density and total porosity, i.e. existence of nanoparticles is always resulted in a pore refinement, filling ability and a lower permeability, in addition to a higher mechanical performance $[1,8,13,17,53,56,57]$.

The use of nanosilica and/or nanoalumina that were present in GPFA and SF decreased the water absorption or permeability of the hardened cement pastes due to its filing ability and pozzolanic reactivity [58-64]. A decrease in water absorption or permeability of cement composites containing nanosilica or nanoalumina or generally nanomaterials was reported due to the pore filling effect of the nanomaterials coupled with enhancement of the interfacial transition zone between the aggregate and cement matrix $[59,61,62]$. Furthermore, the decline in the rate of permeability of cement and/or concrete containing nanosilica was also due to the important production of other calcium silicate hydrates which results in refinement of the microstructure and the relating reduction in permeability, i.e. the use of nanosilica is more effective in the decrease of the water absorption compared to any nanomaterial [59-63].

\section{Conclusions}

The physical and chemo/mechanical properties of the Portland cement (OPC), belite cement (BC) incorporated high pulverized fly ash (HPFA) and Silica fume (SF) were perviously studied in Part I, from which it could be selected the optimum belite cement (B4), that achieved the best results. In Part II, the chemical resistence or durability against $4 \% \mathrm{MgSO}_{4}$ and $4 \%$ $\mathrm{MgCl}_{2}$ aggressive solutions up to 12 months in terms of compressive strength, total sulfate and total chloride was evaluated and studied. The following conclusions could be obtained:-

1 The optimum belite cement (B4) containing $15 \%$ high pulverized fly ash (HPFA) and $5 \%$ silica fume (SF) could be resisted up to 6 months, while that of $\mathrm{BC}$ could be withstood only up to 5 months, and the OPC could not be resisted more than 3 months of immersion in $4 \% \mathrm{MgSO}_{4}$ medium.

2 The compressive strength exhibited by the samples immesed in sulfate solution at 3,5 and 6 months of immersion were $83.81,76.38$ and $91.31 \mathrm{MPa}$, respectively.

3 The same trend was displayed when the same samples were exposed to $4 \% \mathrm{MgCl}_{2}$ solution. 
4 The compressive strength exhibited by the same samples exposed to chloride solution at 3, 5 and 6 months of immersion were 84.49, 82.23 and 93.32 $\mathrm{MPa}$, respectively.

5 Both total sulfate and chloride contents were enhanced with immesion time up to 12 months, and their values were the minimum with $\mathrm{B} 4$ and the maximum with $\mathrm{OPC}$, while with $\mathrm{BC}$ were the midium.

6 Nanomaterials largely improved the resistance of cementing composites. This is essentially contributed to the reduction of the permeability of these composites resulting from its pore filling ability and the pozzolanic reactivity of those nanomaterials with the evolved $\mathrm{Ca}(\mathrm{OH})_{2}$ that is coming from the hydration of di- and trisilicate phases of the cement to form additional CSH.

7 Cementitious composites incorporating nano silica as in HPFA and SF exhibited lower permeability due to their pozzolanic properties together with their capability to act as nucleation sites for cement hydration, i.e. the nanosilica is not sensitive to chemical media. Accordingly, this was positively reflected on physical, chemo/mechanical and durability characteristics.

\section{References}

[1] J. Ren, Y. Lai, J. Gao, Exploring the influence of $\mathrm{SiO}_{2}$ and $\mathrm{TiO}_{2}$ nanoparticles on the mechanical properties of concrete, Construction and Building Materials, 175 (2018) 277-285. [DOI]

[2] H. Zhao, K. Jiang, R. Yang, Y. Tang, J. Liu, Experimental and theoretical analysis on coupled effect of hydration, temperature and humidity in early-age cement-based materials, International Journal of Heat and Mass Transfer, 146 (2020) 118784. [DOI]

[3] G. Li, H. Tan, J. Zhang, X. Deng, X. Liu, Z. Luo, Ground granulated blast-furnace slag/fly ash blends activated by sodium carbonate at ambient temperature, Construction and Building Materials, 291 (2021) 123378. [DOI]

[4] G. Land, D. Stephan, The influence of nanosilica on the hydration of ordinary Portland cement, Journal of Materials Science, 47 (2012) 1011-1017. [DOI]

[5] F. Kontoleontos, P.E. Tsakiridis, A. Marinos, V. Kaloidas, M. Katsioti, Influence of colloidal nanosilica on ultrafine cement hydration: physicochemical and microstructural characterization, Construction and Building Materials, 35 (2012) 347-360. [DOI]

[6] T. Yang, H. Zhu, Z. Zhang, X. Gao, C. Zhang, Q. Wu, Effect of fly ash microsphere on the rheology and microstructure of alkali-activated fly ash/slag pastes, Cement and Concrete Research, 109 (2018) 198-207. [DOI]

[7] T. Yang, H. Zhu, Z. Zhang, Influence of fly ash on the pore structure and shrinkage characteristics of metakaolin-based geopolymer pastes and mortars, Construction and Building Materials, 153 (2017) 284-293. [DOI]

[8] A. Adesina, Durability enhancement of concrete using nanomaterials: an overview, Materials Science Forum, 967 (2019) 221-227. [DOI]

[9] H. Madani, A. Bagheri, T. Parhizkar, The pozzolanic reactivity of monodispersed nanosilica hydrosols and their influence on the hydration characteristics of Portland cement, Cement and Concrete Research, 42 (2012) 1563-1570. [DOI]

[10] M. Heikal, Ali AI, M.N. Ismail, S. Awad, N.S. Ibrahim, Behavior of composite cement pastes containing silica nano-particles at elevated temperature, Construction and Building Materials, 70 (2014) 339-350. [DOI]

[11] S.A.E. Aleem, M. Heikal, W.M. Morsi, Hydration characteristic, thermal expansion and microstructure of cement containing nano silica, Construction and Building Materials, 59 (2015) 151-160. [DOI]

[12] Z. Giergiczny, Fly ash and slag, Cement and Concrete Research, 124 (2019) 105826. [DOI]

[13] H.H.M. Darweesh, Characteristics of Portland Cement Pastes Blended with Silica Nanoparticles, To Chemistry Journal, 5 (2020) 1-14. [DOI]

[14] H. Ozyildirim, C. Zegetosky, Laboratory investigation of nanomaterials to improve the permeability and strength of concrete, Virginia Transportation Research Council, (2010). https ://rosap.ntl.bts.gov/view/dot/20230.

[15] Al-Safy R.A, (2015) Effect of Incorporation Techniques of Nanomaterials on Strength of 
Cement-based Materials\|, The 2nd

International Conference of Buildings, Construction and Environmental Engineering (BCEE2-2015).

[16] P. Duan, C. Yan, W. Zhou, Influence of partial replacement of fly ash by metakaolin on mechanical properties and microstructure of fly ash geopolymer paste exposed to sulfate attack, Ceramics International, 42 (2016) 3504-3517. [DOI]

[17] F. Zou, C. Hu, F. Wang, Y. Ruan, S. Hu, Enhancement of early-age strength of the high content fly ash blended cement paste by sodium sulfate and $\mathrm{C}-\mathrm{S}-\mathrm{H}$ seeds towards a greener binder, Journal of Cleaner Production, (2019) 118566. [DOI]

[18] H.H.M. Darweesh, Nanomaterials: Classification and Properties-Part I, Nanoscience, 1 (2017) 111. [DOI]

[19] J. Yang, J. Huang, Y. Su, X. He, H. Tan, W. Yang, B. Strnadel, Eco-friendly treatment of low-calcium coal fly ash for high pozzolanic reactivity: A step towards waste utilization in sustainable building material, Journal of Cleaner Production, 238 (2019) 117962. [DOI]

[20] J. Yang, H. Hu, X. He, Y. Su, Y. Wang, H. Tan, $\mathrm{H}$, Pan, Effect of steam curing on compressive strength and microstructure of high-volume ultrafine fly ash cement mortar, Construction and Building Materials, 266 (2021) 120894. [DOI]

[21] S. Zhuang; Q. Wang, Inhibition mechanisms of steel slag on the early-age hydration of cement, Cement and Concrete Research 140 (2021) 106283. [DOI]

[22] J. Zhang, H. Tan, M. Bao, X. Liu, Z. Luo, P. Wang, Low carbon cementitious materials: Sodium sulfate activated ultra-fine slag/fly ash blends at ambient temperature, Journal of Cleaner Production, 280 (2021) 124363. [DOI]

[23] H. Bilal, T. Chen, M. Ren, X. Gao, A. Su, Influence of silica fume, metakaolin \& SBR latex on strength and durability performance of pervious concrete, Construction and Building Materials, 275 (2021) 122124. [DOI]

[24] H.H.M. Darweesh, Geopolymer cements from slag, fly ash and silica fume activated with sodium hydroxide and water glass, Interceram - International Ceramic Review, 66 (2017) 226-
231. [DOI]

[25] H.H.M. Darweesh, Physical and Chemo/Mechanical behaviors of fly ash and silica fume high $\beta$-belite cement pastes- Part I, NanoNext, 2 (2021) 1-15. [DOI]

[26] H.H.M. Darweesh, Utilization of CaLignosulphonate Prepared from Black Liquor Waste as a Cement Superplasticizer, Journal of Chemistry and Materials Research (JCMR), 1 (2014) 28-34.

[27] I.B. Topçu, Ö. Ateşin, Effect of high dosage lignosulphonate and naphthalene sulphonate based plasticizer usage on micro concrete properties, Construction and Building Materials, 120 (2016) 189-197. [DOI]

[28] ASTM-C170-90, Standard test method for compressive strength of dimension stone, (1993) 828-830.

[29] H.H.M. Darweesh, Low Heat Blended Cements Containing Nanosized Particles of Natural Pumice Alone or in Combination with Granulated Blast Furnace Slag, NanoProgress, 3 (2021) 38-46.

[30] H.H.M. Darweesh, Extraction of lignin from wastes of sugarcane bagasse and its utilization as an admixture for Portland cement, NanoNEXT, 2 (2021) 13-27. [DOI]

[31] H.H.M. Darweesh, Utilization of Physalis Pith Ash as a Pozzolanic Material in Portland Cement Pastes, Biomaterials, 5 (2021) 1-9. http://www.sciencepublishinggroup.com/j/jb

[32] H.H.M. Darweesh, Characterization of Coir Pith Ash Blended Cement Pastes, Research \& Development in Material science, 15 (2021) 1630-1630. [DOI]

[33] H.H.M. Darweesh, Utilization of Nano-Grain Size Particles of Natural Perlite Rock in Blended Cement-Part II: Durability Against Sulfate Attack, Research \& Development in Material science, 14 (2021) 1512-1519. [DOI]

[34] X. Jiang, Y. Zhang, R. Xiao, P. Polaczyk, M. Zhang, W. Hu, Y. Bai, B. Huang, A comparative study on geopolymers synthesized by different classes of fly ash after exposure to elevated temperatures, Journal of Cleaner Production, 270 (2020) 122500. [DOI]

[35] A.M. Neville, (2011) Properties of Concrete, (5 th $\left.^{\text {edn }}\right)$, Pearson Education Limited, Essex, 
UK. http://www.pearsoned.co.uk.

[36] S.A. Zareei, F. Ameri, F. Dorostkar, M. Ahmadi, Rice husk ash as a partial replacement of cement in high strength concrete containing micro silica: Evaluating durability and mechanical properties, Case Studies in Construction Materials, 7 (2017) 73-81. [DOI]

[37] P.C. Hewlett, M. Liska, (2017) Lea's chemistry of cement and concrete, ( $5^{\text {th }}$ edn), London.

[38] M. Santhanam, M.D. Cohen, J, Olek, Sulfate attack research-whither now?, Cement and Concrete Research, 31 (2001) 845-851. [DOI]

[39] M. Santhanam, M.D. Cohen, J. Olek, Mechanism of sulfate attack: A fresh look: Part I: Summary of experimental results, Cement and Concrete Research, 32 (2002) 915-921. [DOI]

[40] H.H.M. Darweesh, Saw dust ash substitution for Portland cement pastes-Part II: Chemical resistance against sulfate attack, Indian Journal of Engineering, 17 (2020) 396-407. www.discoveryjournals.org

[41] P.K. Mehta, Sulfate attack on concrete separating myths from reality, American Concrete Institute (ACI), 22 (2000) 57-61. [DOI]

[42] Y. Shen, D. Yang, M, Zhang, J. Qian, Active sulfate-rich belite sulfoaluminate cement, Advances in Cement Research, 29 (2017) 166173. [DOI]

[43] H.H.M. Darweesh, Hydration, Strength development and sulphate attack of some cement composites, World Applied Sciences Journal, 23 (2013) 137-144.

[44] K.K. Sideris, A.E. Sawa, J. Papayianni, Sulfate resistance and carbonation of plain and blended cements, Cement and Concrete Composites, 28 (2006) 47-56. [DOI]

[45] A.B. Malkawi, M.F. Nuruddin, A. Fauzi, H. Almattarneh, B.S. Mohammed, Effects of alkaline solution on properties of the HCFA geopolymer mortars, Procedia Engineering, 148 (2016) 710-717. [DOI]

[46] M.B. Kretzer, C. Effting, S. Schwaab, A. Schackow, Hybrid geopolymer-cement coating mortar optimized based on metakaolin, fly ash, and granulated blast furnace slag, Cleaner Engineering and Technology, 4 (2021) 100153.
[DOI]

[47] H. El-Didamony, H.H.M. Darweesh, R.M. Mostafa, Characteristics of pozzolanic cement pastes Part I: Physico-mechanical properties, Silicates Industriels, 73 (2008) 193-200.

[48] U. Sharma, L.P. Singh, B. Zhan, C.S. Poon, Effect of particle size of nanosilica on microstructure of $\mathrm{C}-\mathrm{S}-\mathrm{H}$ and its impact on mechanical strength, Cement and Concrete Composites, 97 (2019) 312-321. [DOI]

[49] M. Nehdi, M, Hayek, Behavior of blended cement mortars exposed to sulfate solutions cycling in relative humidity, Cement and Concrete Research, 35 (2005) 731-742. [DOI]

[50] H. Binici, O. Aksogan, Sulfate resistance of plain and blended cement, Cement and Concrete Composites, 28 (2006) 39-46. [DOI]

[51] M. Wu. Y. Zhang, Y. Ji, G. Liu, C. Liu, W. She, W. Sun, Reducing environmental impacts and carbon emissions: Study of effects of superfine cement particles on blended cement containing high volume mineral admixtures, Journal of Cleaner Production, 196 (2018) 358-369. [DOI]

[52] S. Riahi, A. Nemati, A.R. Khodabandeh, S, Baghshahi, The effect of mixing molar ratios and sand particles on microstructure and mechanical properties of metakaolin-based geopolymers, Materials Chemistry and Physics, 240 (2020) 122223. [DOI]

[53] M. Jalal, A. Pouladkhan, O.F. Harandi, D. Jafari, Comparative study on effects of Class $\mathrm{F}$ fly ash, nano silica and silica fume on properties of high performance self compacting concrete, Construction and Building Materials, 94 (2015) 90-104. [DOI]

[54] Q. Chen, R. Ma, H. Li, Z. Jiang, H. Zhu, Z. Yan, Effect of chloride attack on the bonded concrete system repaired by UHPC, Construction and Building Materials, 272 (2021) 121971. [DOI]

[55] M.H. Zhang, H, Li, Pore structure and chloride permeability of concrete containing nanoparticles for pavement, Construction and Building Materials, 25 (2011) 608-616. [DOI]

[56] J. Yang, Y. Su, X. He, H. Tan, Y. Jiang, L. Zeng, B. Strnadel, Pore structure evaluation of cementing composites blended with coal by- 
products: Calcined coal gangue and coal fly ash, Fuel Processing Technology, 181 (2018) 75-90. [DOI]

[57] M. Saedi, K. Behfarnia, H. Soltanian, The effect of the blaine fineness on the mechanical properties of the alkali-activated slag cement, Journal of Building Engineering, 26 (2019) 100897. [DOI]

[58] A. Ehsani, K. Shabani, M. Nili, A. Ehsani, K. Shabani, Influence of $\mathrm{Nano}_{-} \mathrm{SiO}_{2}$ and microsilica on concrete performance, (2010) http://www.clais se.info/Proce eding s.htm. Accessed March 31, 2020

[59] A.M. Diab, H.E. Elyamany, A.E.M. Abd Elmoaty, M.M. Sreh, Effect of nanomaterials additives on performance of concrete resistance against magnesium sulfate and acids, Construction and Building Materials, 210 (2019) 210-231. [DOI]

[60] T. Ansari rad, J. Tanzadeh, A. Pourdada, Laboratory evaluation of self-compacting fiberreinforced concrete modified with hybrid of nanomaterials, Construction and Building Materials, 232 (2020) 117211. [DOI]

[61] T. Ji, Preliminary study on the water permeability and microstructure of concrete incorporating nano-SiO 2 , Cement and Concrete Research, 35 (2005) 1943-1947. [DOI]

C. Ma, B. Zhao, L. Wang, G. Long, Y. Xie, Clean and low-alkalinity one-part geopolymeric cement: Effects of sodium sulfate on microstructure and properties, Journal of Cleaner Production, 252 (2020) 119279. [DOI]

[63] J.G. Jang, H.K Lee, Microstructural densification and $\mathrm{CO}_{2}$ uptake promoted by the carbonation curing of belite-rich Portland cement, Cement and Concrete Research, 82 (2016) 50-57. [DOI]

[64] S. Maheswaran, S. Kalaiselvam, S.K.S. Saravana-Karthikeyan, C. Kokila, G.S. Palani, $\beta$-Belite cements ( $\beta$-dicalcium silicate) obtained from calcined lime sludge and silica fume, Cement and Concrete Composites, 66 (2016) 57-65. [DOI]

\section{Acknowledgement}

Author wishes to express this deep thanks for National Research Centre for helping to obtain materials, processing, preparing, molding and measuring all of the obtained data of the study, and moreover for financial assistance.

\section{Funding}

No funding was received for conducting this study.

\section{Does this article screened for similarity? Yes}

\section{Conflict of interest}

The Author has no conflicts of interest to declare that they are relevant to the content of this article.

\section{About the License}

(c) The author 2021. The text of this article is open access and licensed under a Creative Commons Attribution 4.0 International License. 